\title{
Studi potensi hutan mangrove di Pulau Serangan sebagai kawasan ekowisata
}

\author{
I Ketut Darma Kusuma Artha ${ }^{1}$, Ni Wayan Febriana Utami²* I Gusti Alit Gunadi3
}

1. Prodi Arsitektur Pertamanan, Fakultas Pertanian, Universitas Udayana, Indonesia 80232

2. Prodi Agroekoteknologi, Fakultas Paertanian, Universitas Udayana, Indonesia 80232

*E-mail: wayan_febriana@unud.ac.id

\begin{abstract}
Study on the potency of mangroves forest in Serangan Island as ecotourism area in South Denpasar District, Denpasar, Bali. Mangrove Forest on Serangan Island is an area managed by PT.Bali Turtle Island Development (BTID) which is a government land under the supervision of the Bali Provincial Forestry Agency (Dinas Kehutanan Provinsi Bali) and Nature Resource Conservation Center (BKSDA). The total area of mangrove forest about of 33 hectares, the mangrove forest in Serangan Island indicate to have biophysic potency such diversity of mangrove species and diversity of fauna. The purpose of this study is to identify the biodiversity of mangrove forests and to assess the suitability of mangrove forests as ecotourism areas. The method used in this research was the conformity analysis proposed by Bahar (2004) and Yulianda (2007) to assess the potency of mangrove forest with biophysical approach. The results of this study found that the area of mangrove forest on Serangan Island was dominated by mangrove species Sonneratia and Rhizopora, with diversity of fauna found such as birds, reptiles, and marine biota at each point of observation area. The tourist suitability index $(\mathrm{k})$ of mangrove forest was 153 and belong to medium category or potentially as an ecotourism area. Recommendation for ecotourism development area of mangrove forest consist of basic concept of development which were buffer area and eco-tourism area. Then ecotourism activities were develop e.g natural interpretation, nature viewing, bird watching, photo hunting, board walks, and fishing. In addition, support from local community and tourists around the mangrove forest was very much to developed Serangan Island as an ecotourism area.
\end{abstract}

Keywords: biodiversity, ecotourism, mangroves forest. Serangan islandl

\section{Pendahuluan}

Pariwisata diposisikan sebagai salah satu sektor andalan dalam pembangunan nasional Indonesia. Salah satu bentuk produk pariwisata sebagai turunan dari konsep pembangunan pariwisata yang berkelanjutan adalah konsep pengembangan ekowisata. Ekowisata menawarkan kesatuan nilai berwisata yang terintergrasi antara keseimbangan menikmati keindahan alam dan upaya melestarikannya. Ekowisata dapat berperan aktif didalam memberikan solusi menyelesaikan permasalahan yang mungkin terjadi dalam pengembangan kawasan pariwisata. Fokus utama dari pengembangan model ekowisata tersebut didasarkan atas potensi dasar kepariwisataan, alam, dan budaya yang dikedepankan.

Pulau Serangan merupakan pulau yang berada di selatan Pulau Bali yang terletak pada jalur pariwisata Sanur, Kuta, dan Nusa Dua. Wilayah ini merupakan kawasan strategis pengembangan pariwisata dimana menurut Dinas Pariwisata Daerah Provinsi Bali (Disparda Bali) tahun 2017 terdapat sebanyak 28.005 wisatawan dalam setahun atau merupakan destinasi wisata yang memiliki kunjungan tertinggi keempat di kota Denpasar yang diikuti oleh Museum Lemayur, Taman Budaya, Prasasti Blanjong, Pasar Kumbasari, Museum Sidik Jari, dan Hutan Bakau. Selain itu, pengembangan Pulau Serangan menjadi kawasan pariwisata didukung juga oleh potensi eksisting yang terdapat di Pulau Serangan yaitu akses yang dekat dengan Bandara Internasional Ngurah Rai, Pelabuhan Benoa dan Jalur jalan By Pass Ngurah Rai.

Kawasan Pulau Serangan memiliki kawasang hutan mangrove yang termasuk dalam kawasan hutan lindung di Bali dengan luas total 98 ha atau sekitar 0,5\% dari luas total hutan mangrove yang berada pada kawasan hutan lindung di Bali. Untuk kawasan Hutan mangrove yang berada dalam kawasan khususnya di kawasan PT. Bali Turtle Island Development (PT. BTID) memiliki total luas 33 ha. Saat ini, vegetasi mangrove yang berada di dalam kawasan PT. BTID didominasi oleh jenis bakau Sonneratia. Tanaman ini 
merupakan jenis tanaman pioneer dengan ciri khas sistem perakaran nafas dengan akar yang berbentuk kerucut tumpul dan muncul kepermukaan tanah sebagai akar nafas (PT. BTID Bali, 2012). Lebih lanjut, dengan adanya hutan mangrove khususnya pada kawasan PT.BTID menjadikan kawasan ini berpotensi untuk dikembangkan sebagai kawasan ekowisata karena didukung oleh keragaman hayati dan karakteristik fisik kawasan yang salah satunya yaitu terdapat laguna yang menarik bagi jenis satwa seperti jenis burung. Dengan adanya manfaat tersebut, maka perlu dilakukan pengkajian mengenai potensi hutan mangrove untuk pengembangan kawasan ekowisata dengan menilai tingkat kesesuaian kawasan sebagai kawasan wisata dan mengidentifikasi keragaman hayati yang nantinya dimanfaatkan sebagai objek wisata yang dapat dikembangkan.

\section{Metode Penelitian}

\subsection{Waktu dan Lokasi Penelitian}

Penelitian ini dilakukan dari bulan Januari 2018 sampai dengan bulan Maret 2018. Lokasi penelitian adalah Kawasan Hutan Mangrove di Pulau Serangan, Kec. Denpasar Selatan, Provinsi Bali yang memiliki luas 33 ha. (Gambar 1).

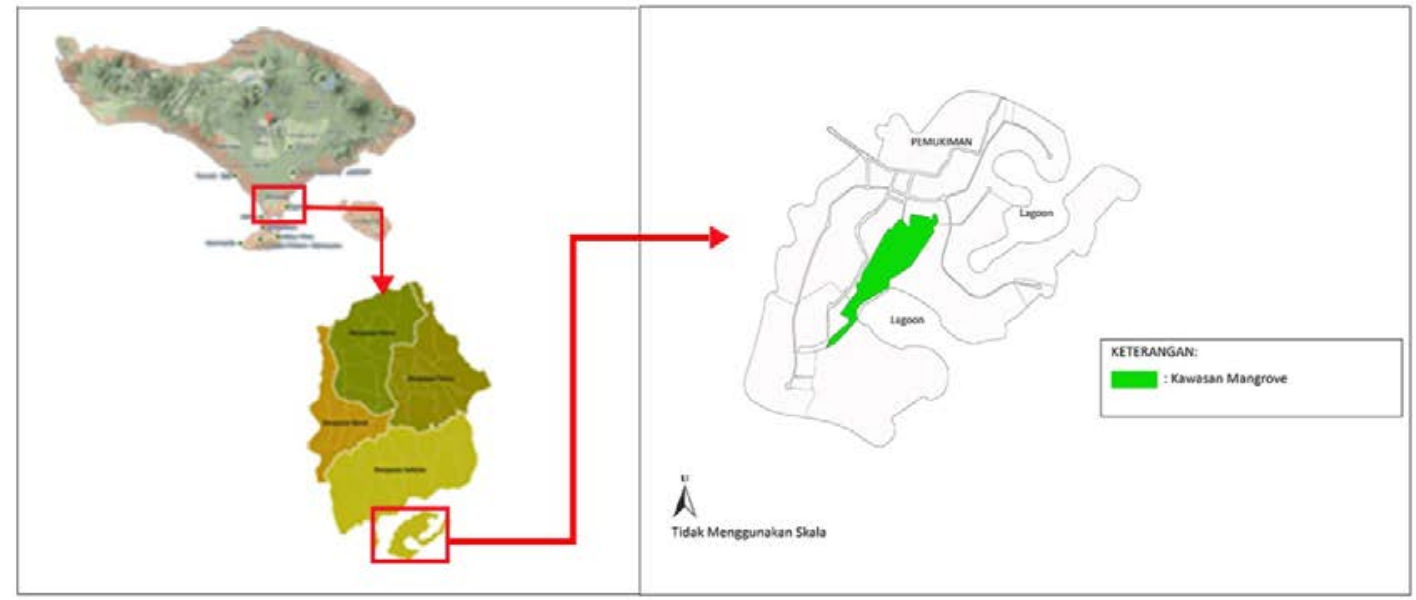

Gambar 1. Lokasi Penelitian

Sumber: PT.BTID (2012)

\section{$2.2 \quad$ Metode}

\subsubsection{Alat dan Bahan}

Alat dan bahan yang digunakan dalam penelitian ini antara lain peta tematik kawasan hutan mangrove, lembar kuesioner persepsi dan karakter masyarakat serangan, lembar kuesioner persepsi dan preferensi wisatawan sekitar hutan mangrove, daftar pertanyaan wawancara kepada Lurah Serangan, dan daftar pertanyaan wawancara kepada pihak staf pengelola kawasan hutan mangrove. Selain itu juga digunakan kamera digital, alat tulis, tali rafia, tiang bambu dan meteran untuk kegiatan observasi di lapangan. Untuk pengolahan data khususnya dalam menghasilkan objek gambar digunakan software antara lain AutoCAD dan Photoshop.

\subsubsection{Metode Penelitian}

Metode penelitian yang digunakan adalah metode penelitian survei. Metode survei adalah penelitian yang dilakukan pada populasi besar atau kecil, tetapi data yang dipelajari adalah data sampel yang diambil dari populasi (Kerlinger, 1973). Teknik yang digunakan untuk memperoleh data pada penelitian ini melalui observasi, wawancara, kuesioner, dan studi pustaka.

\subsubsection{Teknik Pengumpulan Data}

Untuk memperoleh data primer metode yang digunakan yaitu observasi dengan pengambilan data langsung dari lapangan, meliputi identifikasi potensi vegetasi dan satwa. Kemudian metode kuesioner digunakan untuk mendapatkan data karakter dan persepsi masyarakat tentang pengembangan hutan mangrove sebagai kawasan ekowisata dan persepsi wistawan sekitar hutan mangrove untuk pengembangan hutan mangrove sebagai ekowisata. Selain itu dilakukan juga wawancara kepada Lurah Serangan, dan kepada staf pengelola kawasan hutan mangrove untuk mengetahui persepsi masyarakat Serangan dan 
mengetahui kondisi hutan mangrove terkini. Data sekunder diperoleh menggunakan metode studi pustaka dari beberapa sumber yang berkaitan dengan topik penelitian seperti jurnal, tesis, dan buku yang berkaitan dengan ekowisata dan juga informasi tentang data iklim BMKG Ngurah Rai Kuta, data kawasan hutan mangrove dari PT.BTID, dan Forum Peduli Mangrove Bali yang pernah dikaji sebelumnya.

\subsubsection{Metode Analisis}

Studi potensi kawasan hutan mangrove menggunakan metode analisis Bahar (2004) dan Yulianda (2007) dengan 14 kriteria penilaian yaitu dengan pendekatan kerapatan mangrove, jumlah kelompok jenis tumbuhan, jumlah spesies vegetasi mangrove, struktur vegetasi, kekhasan, kelangkaan, ketebalan mangrove, objek biota, lebar perairan pasang surut, panjang perairan pasang surut, frekuensi genangan, karakteristik kawasan, konservasi, aksesibiltas.

\subsubsection{Metode Analisis Kesesuaian Tapak dan Pengumpulan Data Komponen Biofisik Untuk Kawasan Hutan Mangrove}

Tabel 1. Nilai Interval Kesesuaian Berdasarkan Kategori Kesesuaian

\begin{tabular}{lcc}
\hline NO & Kategori & Interval Kesesuaian \\
\hline & Kesesuaian Tinggi & \\
1 & Kesesuaian Sedang & $>200-235$ \\
2 & Kesesuaian Rendah & $100-200$ \\
3 & \multicolumn{1}{c}{ Sumber: Yulianda (2007) dan Bahar (2004), dengan modifikasi }
\end{tabular}

Kesesuaian hutan mangrove mengacu pada nilai interval kesesuaian yang sudah ditetapkan, jika kawasan hutan mangrove memperoleh skor <100 maka kawasan hutan mangrove masuk dalam kategori kesesuaian rendah dikembangkan sebagai kawasan ekowisata sehingga perlu adanya pertimbangan untuk dikembangkan sebagai kawasan ekowisata dilihat dari aspek lingkungan dan aspek wisata yang juga rendah. Jika kesesuaian kawasan hutan mangrove memperoleh skor 100-200, maka termasuk dalam kategori kesesuaian sedang atau berpotensi untuk dikembangkan sebagai kawasan ekowisata. Sedangkan jika memperoleh skor >200 maka kawasan hutan mangrove termasuk dalam kategori kesesuaian tinggi untuk dikembangkan sebagai kawasan ekowisata dan sangat berpotensi dilihat dari aspek lingkungan dan aspek wisata.

a. Pengamatan Kerapatan dan Jenis mangrove

Metode pengukuran yang digunakan untuk mengetahui kondisi kerapatan mangrove adalah dengan menggunakan Metode Transek Garis, dalam pengamatan ini mengambil satu transek garis dengan panjang $30 \mathrm{~m}$ pada setiap titik lokasi pengamatan, dari transek garis tersebut dibuat dua petak contoh dengan ukuran $100 \mathrm{~m}^{2}$ secara acak pada setiap titik lokasi pengamatan, kemudian dari masing-masing petak contoh tersebut diidentifikasi kerapatan mangrove dan jenis vegetasi mangrove.

Petak Contoh (line transect plot) adalah metode pencuplikan contoh populasi suatu ekosistem dengan pendekatan petak contoh yang berada pada garis yang ditarik melewati wilayah ekosistem tersebut (Kepmen LH No.201 Tahun 2004). Adapun langkah-langkah yang dilakukan yaitu:

1. Tarik Transek dari arah laut/perairan ke arah darat dimulai dari bagian terluar mangrove sampai ke daratan. Transek tegak lurus dengan garis pantai sepanjang zonasi hutan mangrove.

2. Pada setiap transek garis, letakkan plot (petak contoh) sebanyak dua buah berbentuk bujur sangkar dengan ukuran $10 \mathrm{~m} \times 10 \mathrm{~m}$ dengan interval antar plot 10 meter.

3. Pengambilan data mangrove untuk menentukan komposisi jenis dan kerapatan mangrove b. Ketebalan Mangrove

Pengukuran ketebalan/lebar mangrove dilakukan secara manual menggunakan peta yang bersumber dari Google Earth dan perangkat lunak AutoCAD untuk mengukur dengan cara melalui penarikan garis sesuai dengan skala gambar yang diambil. Tebal mangrove diukur dari garis terluar ke arah laut/perairan tegak lurus ke arah darat hingga vegetasi mangrove terakhir (Hutabarat dkk, 2009). Tebal mangrove diukur per titik pengamatan. 


\section{c. Objek Biota}

Data objek biota dikumpulkan dari pengamatan langsung di lapangan dan wawancara dengan nelayan yang ada di kawasan guna mendapatkan informasi biota yang mungkin tidak ditemukan atau dilihat pada saat pengamatan secara langsung.

Pengamatan objek biota untuk melihat ada atau tidak biota yang telah ditetapkan pada kriteria penilaian objek biota berdasarkan kriteria penilaian pada tabel matriks kesesuaian ekowisata. Objek biota diamati per titik pengamatan. Pengamatan burung dilakukan selama satu minggu dalam sehari pengamatan dilakukan selama 4 jam yaitu pada waktu pagi hari jam 08.00 Wita - 11.00 Wita dan sore hari jam 15.30 Wita - 17.30 Wita. Pengamatan data biota diamati secara langsung di lapangan, biota yang ditemukan dilakukan pengambilan gambar/foto sampling biota untuk kemudian diidentifikasi jenisnya berdasarkan jurnal-jurnal yang berhubungan dengan penelitian ini.

\section{d. Lebar Perairan Pasang Surut}

Lebar perairan pasang surut pada kawasan hutan mangrove merupakan perairan yang terbentuk mengikuti bentuk alur ekosistem mangrove dan timbul perairan akibat pasang surut air laut. Pengukuran lebar perairan pasang surut menggunakan peta yang bersumber dari Google Earth dan perangkat lunak AutoCAD. Lebar perairan didapatkan dari perhitungan rata-rata lebar masing-masing perairan.

Sampling lebar perairan yang akan dihitung dipilih secara acak dari perairan bagian utara sampai bagian selatan, yaitu titk lokasi pengamatan 1 sampai lokasi titik pengamatan 3. Adapun langkah-langkah pengukuran lebar perairan sebagai berikut:

1. Tampilkan cakupan lokasi penelitian dari Google Earth kemudian simpan gambar lokasi Pulau Serangan dan masukkan gambar ke dalam AutoCAD.

2. Lakukan pengukuran lebar perairan dari satu titik garis perairan ke titik garis perairan lainnya menggunakan polyline pada Autocad.

3. Pengukuran sampling lebar perairan yang akan diukur dipilih secara acak dari perairan bagian utara ke perairan bagian selatan, sehingga didapatkan 15 titik. Lebar perairan diperoleh dari rata-rata sampling lebar perairan yang telah diukur.

e. Panjang Perairan Pasang Surut

Panjang perairan merupakan panjang lintasan tour. Pengukuran panjang perairan menggunakan peta kawasan yang bersumber dari Google Earth. Pengukuran panjang perairan dimulai dari perairan bagian utara dari titik pengamatan 1 sampai dengan perairan bagian selatan pada titik pengamatan 3, pengukuran menggunakan AutoCAD dengan memasukkan gambar Pulau Serangan sesuai skala gambar yang bersumber dari Google Earth kemudian mengukur panjang dengan polyline dari AutoCAD.

\section{f. Frekuensi Genangan}

Frekuensi genangan pada kawasan hutan mangrove menggunakan data Dihidros-AL dan KA-ANDAL Rencana Pembangunan Kawasan Pariwisata di Pulau Serangan,dan juga data observasi pasang surut di kawasan hutan mangrove.

\section{g. Karakteristik Kawasan}

Karakteristik kawasan dinilai dengan mengadopsi matriks kesesuaian ekowisata yang digunakan oleh Bahar (2004). Penilaian karakteristik kawasan dilakukan secara keseluruhan pada tiga lokasi pengamatan di kawasan hutan mangrove. Bahar (2004) mengelompokkan penilaian karakteristik kawasan menjadi 4 ketentuan, yaitu:

1. Adanya obyek alam yang menarik

2. Terdapat panorama indah, panorama atau pemandangan lebih menekankan kepada orientasi keindahan visual suatu daerah.

3. Bentang alam, seperti gunung, bukit, teluk, sungai.

4. Satwa dan tumbuhan langka/dilindungi atau endemik berdasarkan Peraturan Pemerintah Republik Indonesia Nomor 7 Tahun 1999.

h. Aksesibilitas

Mengelompokkan penilaian aksesibilitas dalam 4 ketentuan Bahar (2004), yaitu:

1. Jalan yang bagus untuk mencapai lokasi, minimal aspal.

2. Banyak jalan alternatif untuk mencapai lokasi. 
3. Banyak alat angkut ke lokasi.

4. Terdapat sarana pendukung: dermaga dan terminal.

\subsubsection{Pengolahan Data}

a. Kerapatan

Pengolahan data yang dilakukan yaitu perhitungan kerapatan mangrove.

$\mathrm{Di}=\frac{\mathrm{n}_{\mathrm{i}}}{\mathrm{A}}$

Keterangan:

$\mathrm{Di} \quad=$ Kerapatan Jenis $\mathrm{i}$

$\mathrm{n}_{\mathrm{i}} \quad$ = Jumlah Total Individu dari Jenis

A $\quad=$ Luas Areal Total Pengambilan Contoh $\left(\mathrm{m}^{2}\right)$

b. Jenis Mangrove buku identifikasi.

Mangrove yang telah diambil samplingnya kemudian dilakukan identifikasi menggunakan panduan

\section{c. Objek Biota}

Objek biota diamati secara langsung di lapangan. Biota yang ditemukan dilakukan pengambilan gambar/foto sampling biota untuk kemudian diidentifikasi dengan panduan berdasarkan jurnal - jurnal yang berhubungan dengan penelitian.

d. Lebar Perairan Pasang Surut

Pengolahan data untuk perairan yaitu dengan menghitung nilai rata-rata dari sampling lebar perairan sebagai berikut:

Lebar Perairan $=$

$$
\frac{\mathrm{L} 1+\mathrm{L} 2+\ldots+\mathrm{L} 15}{15}
$$

Keterangan:

$\mathrm{L}=$ Lebar Perairan

$15=$ Jumlah Titik Pengamatan Lebar Perairan yang Ditentukan

e. Panjang Perairan Pasang Surut

Pengolahan data untuk panjang perairan pasang surut yaitu dengan menghitung nilai panjang dari titik pengamatan 1 (perairan bagian utara) sampai dengan titik pengamatan 3 (perairan bagian selatan).

Tabel 2. Matriks Kesesuaian Ekowisata Untuk Hutan mangrove.

\begin{tabular}{|c|c|c|c|c|c|}
\hline No & Kriteria & Bobot & Skor 5 (Tinggi) & $\begin{array}{c}\text { Skor } 3 \\
\text { (Sedang) }\end{array}$ & $\begin{array}{c}\text { Skor } 1 \\
\text { (Rendah) }\end{array}$ \\
\hline 1 & $\begin{array}{l}\text { Kerapatan Mangrove } \\
\left(\mathrm{m}^{2}\right)\end{array}$ & 4 & $>10$ individu/m² & $\begin{array}{l}5-10 \\
\text { individu/m² }\end{array}$ & $<5$ \\
\hline 2 & $\begin{array}{l}\text { Jumlah Kelompok } \\
\text { Jenis Tumbuhan }\end{array}$ & 5 & 5-6 Kelompok & 3-4 Kelompok & $\begin{array}{l}\text { 1-2 } \\
\text { Kelompok }\end{array}$ \\
\hline 3 & $\begin{array}{l}\text { Jumlah Spesies } \\
\text { Vegetasi Mangrove }\end{array}$ & 4 & $\geq 11$ Spesies & 6-10 Spesies & $<6$ Spesies \\
\hline 4 & Struktur Vegetasi & 2 & 3 & 2 & 1 \\
\hline 5 & Kekhasan & 5 & 3 & 2 & 1 \\
\hline 6 & Kelangkaan & 5 & $4-5$ & $2-3$ & 1 \\
\hline 7 & Ketebalan Mangrove & 5 & $>200 \mathrm{~m}$ & $50-200 \mathrm{~m}$ & $<50 \mathrm{~m}$ \\
\hline 8 & Objek Biota & 3 & 4 & $2-3$ & 1 \\
\hline 9 & Lebar Perairan & 1 & $>200 \mathrm{~m}$ & $4-200 m$ & $<4 \mathrm{~m}$ \\
\hline 10 & Panjang Perairan & 1 & $3 \mathrm{~km}$ & $2 \mathrm{~km}$ & $1 \mathrm{~km}$ \\
\hline 11 & Frekuensi Genangan & 2 & $>10$ hari/bulan & 5-10 hari/bulan & $<5$ hari/bulan \\
\hline 12 & Karakteristik Kawasan & 4 & 4 Ketentuan & 2-3 Ketentuan & 1 Ketentuan \\
\hline 13 & Konservasi & 3 & 3 & 2 & \\
\hline 14 & Aksesibilitas & 3 & 4 Ketentuan & 2-3 Ketentuan & 1 Ketentuan \\
\hline
\end{tabular}

Sumber: Bahar (2004) dan Yulianda (2007), dengan pengolahan. 
Penentuan kesesuaian berdasarkan perkalian skor dan bobot yang diperoleh dari setiap parameter. Kesesuaian kawasan dilihat dari tingkat kesesuaian yang diperoleh penjumlahan nilai dari seluruh parameter. (Bahar, 2004). Berdasarkan penelitian yang dilakukan di Desa Tembeling, Kecamatan Teluk Bintan, Kabupaten Bintan tentang Kesesuaian Kawasan Untuk Pengembangan Ekowisata Mangrove bahwa pemberian dengan bobot paling tinggi diberikan pada kriteria yang mempengaruhi nilai dari ekowisata itu sendiri seperti kriteria kerapatan mangrove, ketebalan mangrove, jumlah kelompok jenis vegetasi, jumlah spesies vegetasi, kekhasan kawasan, kelangkaan, dan karakteristik kawasan. Hal tersebut sangat mempengaruhi dalam penilaian tingkat kesesuaian karena ekowisata adalah kegiatan wisata yang menikmati alam dengan keunikan dan keragaman hayati yang menjadi objek wisata. Selain itu pembobotan yang paling rendah diberikan pada kriteria konservasi, struktur vegetasi, frekuensi genangan, lebar perairan pasang surut, dan panjang perairan pasang surut hal tersebut dikarenakan tidak terlalu mempengaruhi dari nilai berwisata pada hutan mangrove. Masing-masing variabel tersebut dibagi menjadi tiga tingkatan, yaitu tinggi dengan skor lima (5), sedang dengan skor tiga (3), dan rendah denga skor 1.

\section{Hasil dan Pembahasan}

\subsection{Kondisi Sosial dan Ekonomi Masyarakat Pulau Serangan}

Mata pencaharian merupakan kegiatan atau pekerjaan yang ditekuni oleh masyarakat untuk bertahan dalam memenuhi kebutuhan hidupnya, dengan kata lain mata pencaharian adalah cara yang dilakukan oleh sekelompok orang sebagai kegiatan sehari-hari guna pemenuhan kehidupan dan menjadi pokok penghidupan baginya. Mengingat Kelurahan Serangan sebelumnya adalah merupakan daerah pesisir, maka mata pencaharian penduduk yang utama adalah sebagai nelayan dengan mencari berbagai hasil laut.

Tabel 3. Mata Pencaharian di Kelurahan Serangan, Tahun 2017

\begin{tabular}{llll}
\hline No & Mata Pencaharian & Jiwa & Presentase (\%) \\
\hline 1 & Peternakan & 60 & 3,90 \\
2 & Perikanan & 770 & 50,03 \\
3 & Industri & 77 & 5,07 \\
4 & Perdagangan & 564 & 34,3 \\
5 & Angkutan dan Komunikasi & 40 & 2,60 \\
6 & Pemerintahan/Jasa & 133 & 8,76 \\
\hline
\end{tabular}

Sumber: BPS Kota Denpasar (2017)

\subsection{Gambaran Umum Kawasan}

Kawasan Hutan Mangrove merupakan kawasan yang dikelola oleh pihak PT. BTID dalam pengawasan Dinas Kehutanan Provinsi Bali dan bekerja sama dengan masyarakat Pulau Serangan dalam melestarikan keberadaan Hutan Mangrove. Kawasan hutan mangrove memiliki total area sebesar 33 ha yang dikelilingi oleh daratan pada sisi utara, selatan, dan barat kawasan. Sedangkan pada sisi timur kawasan berhadapan langsung dengan laguna yang sekarang disebut sebagai Teluk Lebangan. Pulau Serangan termasuk kawasan hutan mangrove memiliki rata-rata suhu $27,4^{\circ} \mathrm{C}$ dan kawasan hutan mangrove berada pada letak geografis $8^{\circ} 44^{\prime} 7.55^{\prime \prime} \mathrm{LS}$ dan $115^{\circ} 13^{\prime} 50.17^{\prime \prime B T}$.

\subsection{Potensi Flora}

Hutan mangrove yang berada di tengah kawasan Pulau Serangan merupakan tipe kawasan mangrove payau. Kawasan Hutan Mangrove berada di sepanjang sungai berair payau hingga hampir tawar, di zona ini biasanya di dominasi oleh komunitas Nypa atau Sonneratia dan juga banyak tersebar jenis Rhizopora di seluruh bagian kawasan hutan mangrove. Menuju arah pantai, campuran komunitas Sonneratia - Nypa dan Rhizopora lebih sering ditemukan. Pada kawasan hutan mangrove ditemukan lima mangrove sejati yaitu Avicenia Lanata, Bruguiera gymnorrhiza, Ceriops tagal, Rhizopora apiculata, Sonneratia alba.

\subsection{Potensi Fauna}

Berdasarkan hasil observasi kawasan hutan mangrove di Pulau Serangan ditemui beragam satwa dan biota yang hidup, beberapa fauna atau biota yang dapat ditemukan adalah biota laut seperti jenis kepiting khususnya jenis-jenis penggali dari genus Cleistocoelema, Macrophtalmus, Metaplax, Ilyoplax, Sesarma, Uca, dan beberapa jenis ikan yang dapat ditemukan di kawasan hutan mangrove di Pulau 
Serangan seperti Tentraodon erythrotenia, Butis butis, Liza subviridis, dan Ambassis buruensis. Jenis burung juga dapat ditemukan pada kawasan hutan mangrove di pulau serangan. Beberapa jenis burung air yang dapat ditemukan seperti Kuntul (Egretta sp.), dan Bangau (Ciconiidae), Belibis (Dendrocygna autumnalis), Kokokan (Butorides striatus), Trinil laut (Actitis hypoleucos), Pecuk Ular Asia (Anhinga melanogaster).

\subsection{Kesesuaian Ekowisata Hutan Mangrove}

Berdasarkan perhitungan kesesuaian kawasan diperoleh nilai indeks kesesuaian wisata untuk ekowisata mangrove di Pulau Serangan yaitu 132. Dari nilai hasil perhitungan pada masing-masing kriteria di setiap titik pengamatan lokasi penelitian tersebut, kemudian digabungkan dan dirata-ratakan dari tiga titik pengamatan yang diukur maka tergolong pada interval kelas kesesuaian sedang atau berpotensi untuk dijadikan kawasan ekowisata.

Tabel 4. Matriks Hasil Kesesuaian Untuk Ekowisata Hutan Mangrove

\begin{tabular}{|c|c|c|c|c|c|}
\hline No & Kriteria & Bobot & Hasil & Skor & Bobot x Skor \\
\hline 1 & $\begin{array}{l}\text { Kerapatan Mangrove } \\
\left(100 \mathrm{~m}^{2}\right)\end{array}$ & 4 & $9,61 \mathrm{indv} / \mathrm{m}^{2}$ & 3 & 12 \\
\hline 2 & $\begin{array}{l}\text { Jumlah Kelompok Jenis } \\
\text { Tumbuhan }\end{array}$ & 5 & 5 Kelompok & 5 & 25 \\
\hline 3 & $\begin{array}{l}\text { Jumlah Spesies } \\
\text { Vegetasi Mangrove }\end{array}$ & 4 & 5 Jenis & 1 & 4 \\
\hline 4 & Ketebalan Mangrove (m) & 5 & $144 m$ & 3 & 15 \\
\hline 5 & Struktur Vegetasi & 2 & 3 & 5 & 10 \\
\hline 6 & Kekhasan & 5 & 3 & 3 & 15 \\
\hline 7 & Kelangkaan & 5 & 1 & 1 & 5 \\
\hline 8 & Objek Biota & 3 & 3 Spesies & 3 & 9 \\
\hline 9 & Lebar Perairan (m) & 1 & $18 m$ & 3 & 3 \\
\hline 10 & Panjang Perairan (km) & 1 & $1 \mathrm{~km}$ & 1 & 1 \\
\hline 11 & Frekuensi Genangan & 3 & 5-10hri/bulan & 3 & 9 \\
\hline 12 & Karakteristik Kawasan & 4 & 3 Ketentuan & 3 & 12 \\
\hline 13 & Konservasi & 3 & 2 & 3 & 9 \\
\hline 14 & Aksesibilitas & 3 & 1 Ketentuan & 1 & 3 \\
\hline \multicolumn{5}{|c|}{ Indeks Kesesuaian Wisata (Ik) } & 132 \\
\hline
\end{tabular}

Hal ini sesuai hasil penelitian yang dilakukan oleh Bahar (2004) tentang Kajian Kesesuaian dan Daya Dukung Ekosistem Mangrove Untuk Pengembangan Ekowisata di Gugus Pulau Tanakeke menyatakan bahwa lokasi yang memiliki kesesuaian sedang berpotensi dikembangkan sebagai kawasan ekowisata.

\subsection{Persepsi dan Karakter Masyarakat Pulau Serangan Dalam Mendukung Pengembangan Ekowisata Hutan Mangrove}

Berdasarkan hasil kuesioner persepsi dan karakter masyarakat serangan dengan laporan studi lapangan di Pulau Serangan oleh Lisa Woinarski (2002) tentang Dampak Pembangunan pada Lingkungan dan Masyarakat di Pulau Serangan bahwa dampak pembangunan yang dilakukan di Pulau Serangan memberikan dampak yang besar terutama dari segi sosial dan lingkungan. Akibat dari pembangunan wisata 
yang dilakukan dengan reklamasi, menyebabkan terjadinya perubahan kondisi lingkungan yang berpengaruh terhadap mata pencaharian masyarakat pulau Serangan yang dominan sebagai nelayan. Rusaknya terumbu karang dan sebagai sumber kehidupan biota laut menyebabkan berkurangnya penghasilan masyarakat sebagai nelayan. Persepsi masyarakat di Pulau Serangan menyatakan bahwa masyarakat setuju jika hutan mangrove dikembangkan sebagai kawasan wisata mengingat hal tersebut dapat menciptakan lapangan kerja yang baru sekaligus menambah penghasilan masyarakat dan dapat melestarikan kawasan hutan mangrove sebagai tempat hidup biota laut.
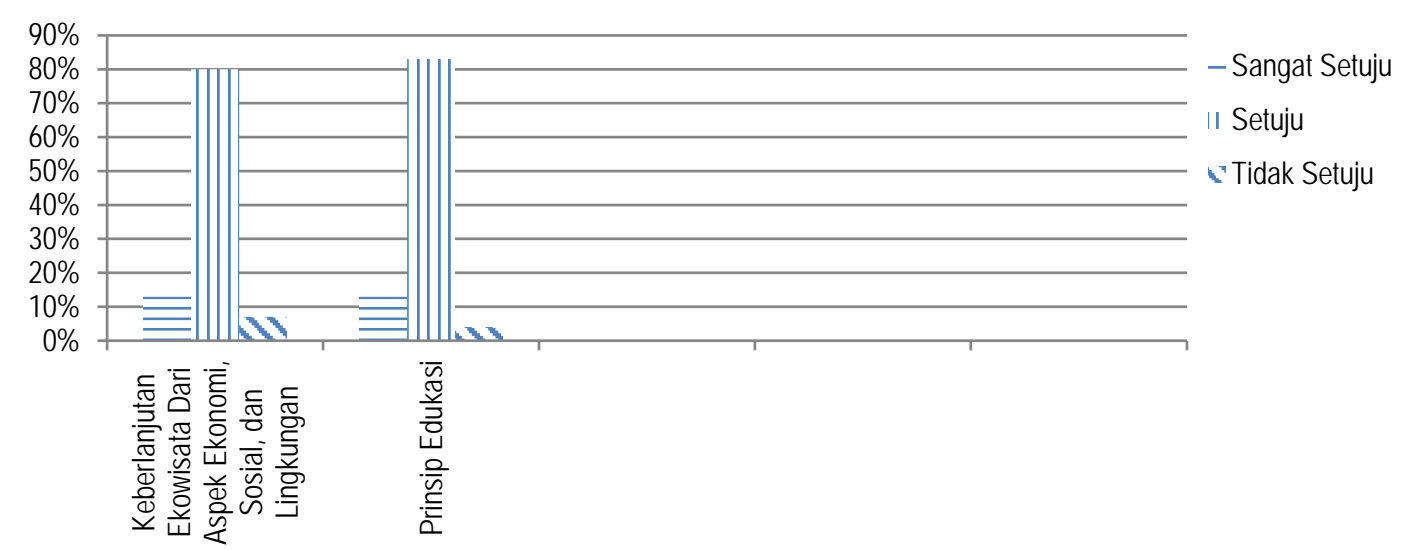

Gambar 2. Persepsi dan Karakter Masyarakat Pulau Serangan Dalam Mendukung Pengembangan Ekowisata Hutan Mangrove

\subsection{Persepsi dan Preferensi Wisatawan Sekitar Kawasan Hutan Mangrove}

Berdasarkan persepsi dan preferensi wisatawan sekitar hutan mangrove didapatkan hasil bahwa tujuan wisatawan ke pulau serangan untuk berwisata, informasi hutan mangrove yang didapatkan bersumber dari internet. Wisatawan lebih memilih jalur tracking pedestrian dan jalur tracking canoe untuk memfasilitasi kawasan hutan mangrove. Wisatawan juga menyatakan nyaman jika berkunjung ke kawasan hutan mangrove, dan menyatakan bahwa kawasan hutan mangrove berpotensi untuk dikembangkan sebagai kawasan ekowisata. Sesuai dengan penelitian Bahar (2004) bahwa kegiatan ekowisata hutan mangrove perlu adanya jalur atau akses seperti jalan papan (board walks) merupakan fasilitas utama untuk memudahkan wisatawan dalam menikmati kawasan hutan mangrove dan juga berhubungan dengan kegiatan wisata lainnya seperti bird watching, photo hunting, interpretasi alam, dan memancing. (Gambar 3)

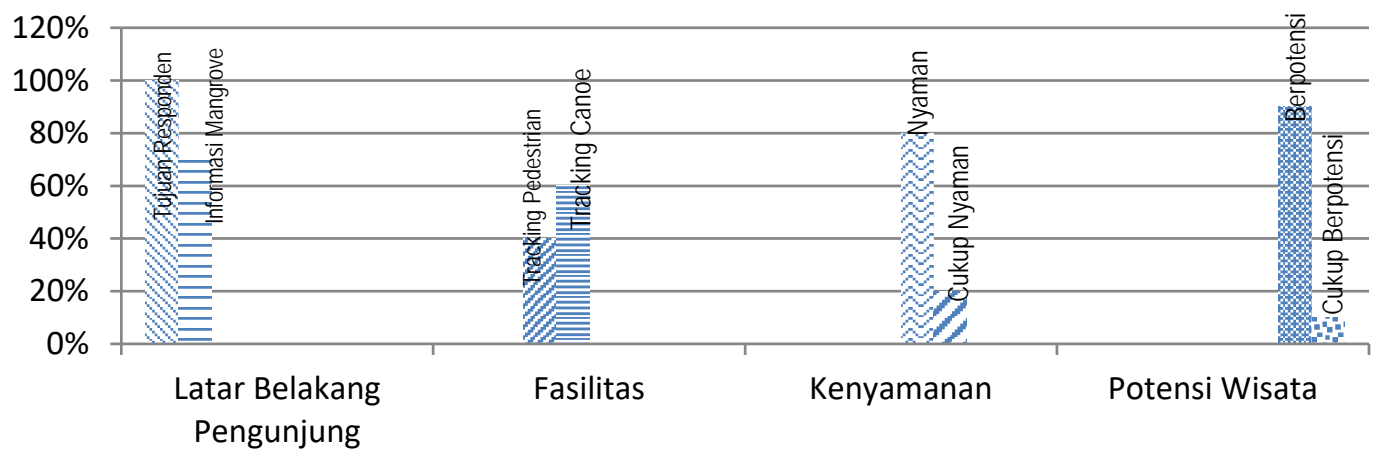

Gambar 3. Persepsi dan Preferensi Wisatawan Sekitar Kawasan Hutan Mangrove 


\section{Sintesis Pengembangan Ekowisata Hutan Mangrove}

Sesuai dengan potensi biofisik yang terdiri dari keragaman vegetasi mangrove dan keragaman biota. Kawasan hutan mangrove di Pulau Serangan termasuk dalam kategori kesesuaian sedang atau berpotensi untuk dikembangkan sebagai kawasan ekowisata berdasarkan hasil matriks analisis kesesuaian kawasan hutan mangrove. Kegiatan ekowisata yang mungkin dilakukan dapat diketahui dengan mengidentifikasi potensi sumberdaya ekosistem mangrove di Pulau Serangan. Hasil inventarisasi potensi ekowisata di ekosistem mangrove tersebut akan menghasilkan beberapa potensi kegiatan ekowisata, namun tidak semua potensi ekowisata tersebut dapat dikembangkan karena tidak sesuai dengan kondisi alam yang lain yang menjadi penghambat.

Tabel 5. Analisis Kegiatan Ekowisata Terpilih

\begin{tabular}{lccccccc}
\hline Faktor yang \\
berpengaruh
\end{tabular}

Keterangan: + = faktor pendukung, - = faktor penghambat, $t=$ tidak potensial, $\mathrm{p}=$ potensial

Sumber: Bahar (2004)

Sesuai dengan penelitian Bahar (2004) di Kajian Kesesuaian Hutan Mangrove Sebagai Ekowisata di Gugus Pulau Tanakeke bahwa kondisi hutan mangrove dengan dataran rendah dan tunggang pasang air laut yang rendah menjadi penghambat untuk kegiatan bersampan, karen dapat menyebabkan terperangkapnya perahu di tengah hutan mangrove sehingga menjadi tidak potensial.

\subsection{Kegiatan Ekowisata Terpilih}

Kegiatan ekowisata membutuhkan lokasi yang membutuhkan lokasi yang memiliki daya tarik keindahan pemandangan alam (view) flora dan fauna hutan mangrove yang alami, aman dari gangguan satwa liar dan faktor-faktor fisik yang bisa mengurangi kelancaran aktivitas ekowisata. Kegiatan ekowisata yang bernuansa rekreasi yang sesuai dengan potensi di hutan mangrove. Pulau Serangan yang berada pada kawasan PT.BTID yang merupakan kegiatan ekowisata yang potensial adalah aktifitas interpretasi alam, memandang alam, memotret, jalan-jalan (board walks), memancing, dan mengamati burung (bird watching).

\subsection{Pengembangan Ekowisata Hutan Mangrove}

\subsubsection{Konsep Dasar Pengembangan}

Kawasan hutan mangrove di Pulau Serangan perlu dikembangakan dengan konsep ekowisata, aktivitas wisata dikembangkan dengan tetap memperhatikan kelestarian sumberdaya tapak dan memberikan pengalaman serta pengetahuan tentang mangrove dari segi kondisi fisik hutan mangrove dan biota yang hidup di dalamnya. Ruang merupakan wadah untuk melakukan aktifitas, program ruang yang diakomodasikan pada tapak didasarkan konsep ekowisata, perlindungan sumber daya alam, keberadaan obyek dan atraksi wisata tapak serta fungsi yang akan diterapkan (Zain, 2008). Maka Ruang yang akan 
dikembangkan terdiri dari ruang penyangga dan wisata yang disajikan pada Gambar 3. Aktifitas wisata diarahkan menjadi aktivitas kelompok yang lebih berorientasi pada jalur. Jalur berfungsi untuk melakukan interpretasi dengan menikmati pemandangan serta pengamatan sumberdaya alam.

\section{Ruang Penyangga}

Ruang penyangga merupakan area perlindungan terhadap flora dan fauna hutan mangrove. Ruang penyangga yang disediakan untuk ekowisata mangrove. Ruang penyangga diarahkan untuk melakukan aktivitas wisata berupa jalan-jalan (board walks), bersantai, dan kegiatan ekowisata lainnya. Aktifitas wisata yang dilakukan pada ruang ini dimaksudkan untuk aktifitas wisata pendidikan melalui interpretasi terhadap vegetasi hutan mangrove.

\section{Ruang Ekowisata}

Ruang ekowisata adalah ruang yang digunakan untuk melakukan aktifitas utama wisata. Ruang ini terdapat objek dan atraksi wisata, sehingga ruang ini digunakan sebagai ruang untuk melakukan aktifitas wisata pendidikan maupun non pendidikan. Aktifitas wisata yang dikembangkan berupa aktifitas seperti memotret, board walks, memandang alam, bird watching, interpretasi alam, aktifitas tersebut disesuaikan dengan fasilitas yang akan direncanakan seperti menara, gazebo, papan pengintip, papan untuk jalan-jalan agar menunjang kegiatan wisata tersebut dan mendapatkan kepuasan pengunjung yang optimal.

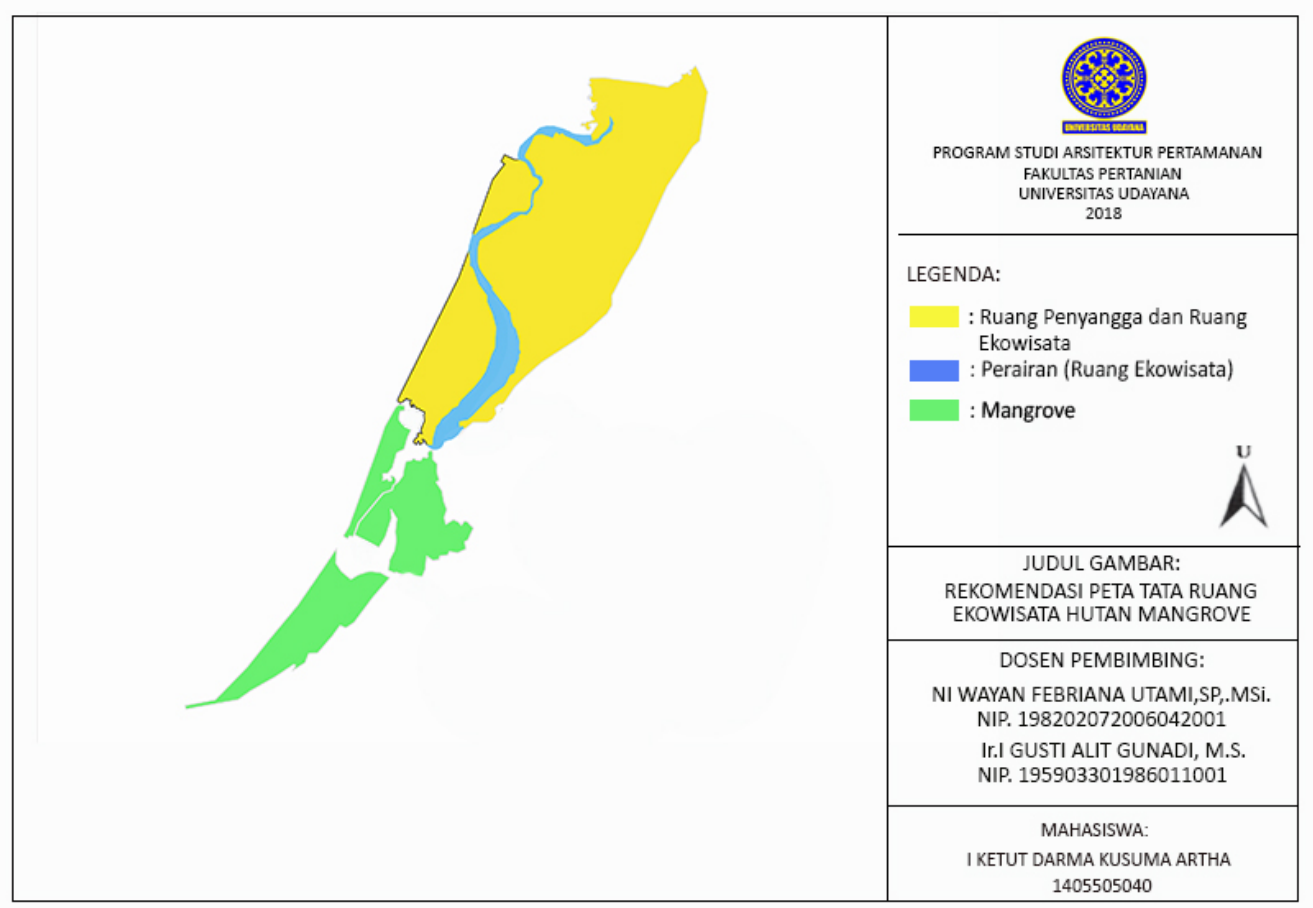

Gambar 4. Peta Tata Ruang Pengembangan Ekowisata

\subsubsection{Potensi Daya Dukung Kawasan}

Kegiatan ekowisata di dalam ekosistem mangrove merupakan kegiatan yang saling berhubungan satu dengan yang lain, sehingga dalam setiap kegiatan ekowisata dapat menggunakan fasilitas yang sama. Misalnya, kegiatan memotret dan interpretasi alam dapat dilakukan secara bersamaan di jalan papan (board walks). Demikian pula dengan penggunaan menara untuk kegiatan memandang alam dan memotret juga dapat dilakukan secara bersamaan. Pengadaan fasilitas yang berfungsi ganda tersebut dilakukan untuk mengurangi pembangunan fasilitas ekowisata yang dapat melebihi daya dukung kawasan, selain itu pengadaan fasilitas yang berfungsi ganda tersebut akan mengurangi investasi untuk pengadaan fasilitas, namun fasilitas yang ada tersebut diharapkan tidak akan mengurangi pengalaman ekowisatawan dengan memanfaatkan sarana secara optimal. Adapun fasilitas ekowisata yang harus diadakan untuk mendukung kegiatan ekowisata terpilih adalah seperti menara dan jalan papan (board walks), papan pengintip, dan gazebo. 


\section{Simpulan dan Saran \\ 5.1 Simpulan}

Kawasan Hutan Mangrove di Pulau Serangan yang berada pada kawasan milik PT.BTID memiliki potensi vegetasi yaitu terdiri dari 5 tanaman mangrove sejati yaitu Sonneratia alba, Rhizopora apiculata, Avicenia lanata, Ceriops tagal, Brugueirea gymnorrhiza, dan kawasan pada kawasan hutan mangrove didominasi oleh tanaman Sonneratia alba dan Rhizopra apiculata. Potensi satwa yang ditemukan pada kawasan mangrove terdiri dari burung jenis Egretta dan bangau Cociidinae, biota laut seperti jenis kepiting penggali (Cleistocoelema, Macrophtalmus, Metaplax, Ilyoplax, Sesarma, dan Uca), dan reptil. Kawasan ekowisata hutan mangrove di Pulau Serangan memiliki kesesuaian sedang dengan indeks kesesuaian wisata $\left(\mathrm{l}_{\mathrm{k}}\right) 132$ yang berarti berpotensi untuk dikembangkan sebagai kawasan ekowisata.

5.2 Saran

Kawasan hutan mangrove yang ada di Pulau Serangan agar dapat dikelola dan dilestarikan dengan baik oleh masyarakat Pulau Serangan maupun pemerintah daerah. Rekomendasi yang dapat dilakukan terhadap kawasan hutan mangrove yaitu lebih memaksimalkan kegiatan penanaman jenis vegetasi mangrove dan upaya pemeliharaan kawasan terhadap lingkungan hutan mangrove, vegetasi, dan fauna.

\section{Daftar Pustaka}

Bahar, A, 2004. Kajian Kesesuaian dan Daya Dukung Ekosistem Mangrove Untuk Pengembangan Ekowisata di Gugus Pulau Tanake Kabupaten Takalar Sulawesi Selatan, Tesis, Sekolah Pasca Sarjana Program Studi Pengelolaan Sumberdaya Pesisir dan Lautan, Institut Pertanian Bogor.

Bali Turtle Island Development Anonym.2012. Selayang Serangan Tersedia online: http://btid.co.id/pulau serangan/ (Diakses 18 September 2017).

BMKG Ngurah Rai, Denpasar Selatan, Bali. 2018. Data Suhu Desa Suwung Kangin, Denpasar Selatan, Bali. BPS Kota Denpasar, 2014. Data Mata Pencaharian Masyarakat Serangan .2014

Dinas Pariwisata Daerah provinsi Bali. 2012. Jumlah Wisatawan Pada Kunjungan Obyek-Obyek Wisata di Bali Available Online at: (www.disparda.baliprov.go.id/id/Statistik4) (Diakses 27 Juli 2018)

Forum Peduli Mangrove Bali.2012. Fakta Mangrove di Bali Available online at: (http://fpmbali.org/mangrove/bali) (Diakses 18 September 2017)

Kerlinger. F. N. (1973). Founding of Behavior Research, Holt. Rinchart and Winston Inc. New York.

Muntasib, E.K.S.H. 2005. Pengembangan ekowisata Indonesia dalam rangka meningkatkan devisa negara dari sektor pariwisata. Prosiding Seminar Ekowisata, Pekan IImiah Kehutanan Nasional. Badan Eksekutif Mahasiswa, Fakultas Kehutanan, IPB. Bogor. 39p.

Nunung Rozalina, Arif Pratomo, Apdilah Donny. 2014. Kesesuaian Kawasan Untuk Pengembangan

Ekowisata Mangrove Berdasarkan Biofisik di Desa Tembeling Kecamatan Teluk Bintan Kabupaten Bintan. Tersedia Online: http://jurnal.umrah.ac.id (Diakses 7 Agustus 2018)

Peraturan Pemerintah Tahun .1999. Peraturan Pemerintah Republik Indonesia No.7 Tahun 1999 Tentang Pengawetan Jenis Tumbuhan dan Satwa

Woinarski Lisa. 2002. Pulau Serangan: Dampak Pembangunan Pada Lingkungan dan Masyarakat. Tersedia Online: http://www.acicis.edu.au (Diakses 7 Agustus 2018).

Yulianda, F.2007. Ekowisata bahari sebagai alternatif pemanfaatan sumber daya pesisir berbasis konservasi. Makalah Seminar Sains pada Departemen Manajemen Sumberdaya Perairan. Fakultas Perikanan dan IImu Kelautan IPB. Bogor.

Zain, A.F.M. 2008. Perencanaan dan desain lanskap tapak ekowisata. Ekoturisme: Teori dan Praktek. Bogor. 1:133-167p 